\title{
Antisense oligodeoxynucleotides targeting ATM strengthen apoptosis of laryngeal squamous cell carcinoma grown in nude mice
}

\author{
Jun Feng ${ }^{1,4 \dagger}$, Jian Zou' ${ }^{1 \dagger}, \mathrm{Li} \mathrm{Li}^{2}$, Yongsheng Zhao ${ }^{3}$ and Shixi Liü
}

\begin{abstract}
Background: To conserve laryngeal function and elevate living quality of laryngeal squamous cell carcinoma (LSCC) patients, we designed antisense oligodeoxynucleotides (AS-ODNs) to reduce expression of ATM and to enhance the apoptosis of hep-2 (Human epidermoid laryngeal carcinoma) cells to radiation in vitro and in vivo.

Methods: The expression of ATM mRNA and protein in hep-2 cells were examined by real-time quantitative PCR and western blotting respectively. Clonogenic survival assay was carried out to detect the survival ability of hep-2 cells after irradiation, and analyzed the cell apoptosis by flow cytometry. The volume of solid tumors was measured, while TUNEL assay and western blotting used to analyze cell apoptosis and protein expression after irradiation.
\end{abstract}

Results: The relative ATM mRNA and protein expression in hep-2 cells treated with ATM AS-ODNs were decreased to $11.03 \pm 2.51 \%$ and $48.14 \pm 5.53 \%$ of that in untreated cells respectively $(P<0.05)$. After irradiation, the survival fraction (SF) of cells treated with ATM AS-ODNs was lower than that of other groups at the same dose of radiation $(P<0.05)$. The inhibition rate in hep-2 cells solid tumor exposed to $X$-ray alone was $5.95 \pm 4.52 \%$, while it was $34.28 \pm 2.43 \%$ in the group which irradiated in combination with the treatment of ATM AS-ODNs $(P<0.05)$. The apoptotic index for the group irradiated in combination with ATM AS-ODNs injection was $17.12 \pm 4.2 \%$, which was significantly higher than that of others $(P<0.05)$.

Conclusion: AS-ODNs of ATM reduce ATM expression and enhance hep-2 cells apoptosis to radiation in vitro and in vivo.

Keywords: ATM Antisense oligodeoxynucleotides, apoptosis, squamous cell carcinoma

\section{Introduction}

With advanced technique development in treatments of LSCC, radiotherapy is superior in its ability to conserve function in the treatment of initial laryngeal squamous cell carcinoma (LSCC). However, because of laryngeal cancer radiation resistance, which result in the low effectiveness and high recurrence when treated with radiotherapy alone $[1,2]$. So it is important significance to improve the LSCC radiosensitivity. Hep- 2 cells, or laryngeal squamous cell carcinoma cell lines, are helpful

\footnotetext{
* Correspondence: fjlx8888@sohu.com

† Contributed equally

${ }^{1}$ From the Department of Otolaryngology-Head and Neck Surgery, West

China hospital of Sichuan University, Chengdu, PR China 610041

Full list of author information is available at the end of the article
}

in studying the biological behavior of LSCC. In the latest study, Hep-2 cells were found to be resistant to radiotherapy [3]. Ataxia-telangiectasia (A-T) is characterized by impaired recognition and repair of DNA damage and increased sensitivity to ionizing radiation (IR) in cancer, and neurodegeneration [4]. The cytotoxicity of ionizing radiation is mainly mediated through the generation of DNA-double strand break (DSB) as evidenced by the pronounced radiosensitivity of cells and organisms defective in the machinery of DSB repair[5-7]. Thus, restraint of DSB repair reveals a mechanism to enhance the cytotoxicity of IR in tumour cells. ATM (ataxia telangiectasia mutated) is a key protein responsible for arresting the cell cycle in response to DNA damage and has a role in genetic stability and cancer susceptibility

\section{() Biomed Central}


[8-10]. ATM protects the integrity of the genome at different levels: (1) it mediates arrest of the cell cycle at $G_{1} / S, S$, and $G_{2} / M$ to prevent the processing of damaged DNA; (2) it activates DNA-repair pathways; and (3) it induces apoptosis if the DNA damage is so detrimental that normal cell function can no longer be rescued [11-15]. Zou and colleagues have shown that antisense inhibition of ATM gene enhances the radiosensitivity of head and neck squamous cell carcinoma in mice $[16,17]$. Sak A reported that the kinase activity of DNA-PKcs could be specifically inhibited by As-ODNs and resulted in marked inhibition of DNA-Dsb rejoining and radiosensitization of human non-small cell lung cancer (NSCLC) cell line [18]. Leonard CE's study showed that the Paclitaxel could enhance the radiosensitivity of squamous carcinoma cell line of the head and neck in vitro [19]. However, there were no reports about the antisense oligodeoxynucleotides of ATM strengthening radio-induced apoptosis of laryngeal squamous cell carcinoma grown in nude mice. Therefore, we designed to study whether reduction of ATM expression after antisense oligodeoxynucleotides (AS-ODNs) treatment would result in enhanced radio-induced apoptosis of Hep-2 cells from BALB/c-nu/nu mice.

\section{Methods \\ Reagents}

Lipofectamine 2000, Opti-MEM I medium and Trizol kit were bought from Invitrogen Company (Carlsbad, CA, USA), and anti-GAPDH Monoclonal Antibody from SAB (Beijing, China). SYBR ExScript RT-PCR Kit, SYBR Green Master Mix, AnnexinV-FITC-PI, RPMI1640 media and 10\% heat-inactivated fetal bovine serum (FBS) were purchased from Takara Biotechnology Company (Dalian, China). ATM monoclonal antibody was bought from Santa Cruz Biotechnology (Santa Cruz, CA, USA). BCIP/NBT alkaline phosphatase substrate kit IV was purchased from Vector laboratories (Burlingame, CA, USA). TUNEL apoptosis detection kit was bought from Roche Company (Shanghai, China).

\section{Cell lines and mice}

Hep-2 cell line was obtained from the laboratory of Head and Neck at Sichuan University. The cells were maintained in RPMI-1640 medium, supplemented with $10 \%$ heat-inactivated fetal bovine serum, $100 \mu \mathrm{g} / \mathrm{mL}$ streptomycin, and $100 \mathrm{U} / \mathrm{mL}$ penicillin $\mathrm{G}$ in a humidified atmosphere of $5 \% \mathrm{CO}_{2}$ and $95 \%$ air at $37^{\circ} \mathrm{C}$. Female $\mathrm{BALB} / \mathrm{c}-\mathrm{nu} / \mathrm{nu}$ mice, aged 3-4 weeks, weighing 18-22 g, were obtained from the animal centre of West China Medical School and were maintained in the animal facility at West China Medical School, Sichuan University in accordance with nation's related regulations and animal welfare requirements.
Synthesis of oligodeoxynucleotides (ODNs) and selection of target sequences

AS-ODNS, sense (Sen) and mismatch (Mis) ODNs were synthesized by Shanghai Sangon Biological Engineering Technology \& Services (Shanghai, China). The sequences were as follows: AS (5'-GTACTAGACTCATGGTTCACAATTT-3'); Sen (5'-AAATTGTGAACCATGAGTCTAGTAC-3') and Mis (5'-AAAATGTAA ACCATAAGTCTAGAAC-3'). All the ODNs were chemically modified to phosphorothioate ODNs by substituting the oxygen molecules of the phosphate backbone with sulfur.

\section{Transfection of ODNs in Hep-2 cells}

Hep- 2 cells at a density of $2 \times 105$ cells $/ \mathrm{ml}$ were plated in 6-cell plates for overnight incubation. Cells were maintained in RPMI-1640 medium supplemented with $10 \% \mathrm{FBS}$ at $37^{\circ} \mathrm{C}$ and $5 \% \mathrm{CO} 2$. After grew to $70-80 \%$ confluent, cells were replenished with incomplete RPMI-1640 medium, then treated with ATM AS-ODNs, ATM Sen-ODNs and Mis-ODNs. The procedures were as follows: 0.8 ug of ATM AS-ODNs, Sen-ODNs, MisODNs and $2 \mathrm{mg} / \mathrm{ml}$ Lipofectamine 2000 were added to Opti-MEM I medium separately, and incubated for 5 min at room temperature. Then liposome and ODNs were mixed and incubated at room temperature for 20 min. Hep- 2 cells were washed again with Opti-MEM I medium before transfection. The liposome ODNs complexes were carefully plated on the cells, and incubated at $37^{\circ} \mathrm{C}, 5 \% \mathrm{CO} 2$. After 6 hours transfected cells were washed twice with PBS. With the medium replaced with fresh RPMI-1640 medium supplemented with 10\% FBS, the cells were incubated at $37^{\circ} \mathrm{C}$ overnight. A second ODNs incubation was performed before cells were exposed to radiation.

\section{Real-time quantitative PCR analysis}

According to the manufacturer's recommendations total RNAs were extracted from cultured Hep-2 cells using Trizol reagent. One-step RT-PCR was performed in LightCycler-RNA Amplification Kit SYBR Green I. ATM was amplified with the sense primer: (5'GACCGTGGAGAAGTAGAATCAATGG-3' and the anti-sense primer: 5'-GGCTCTCTCCAGGTTCGTT TGC-3'). GAPDH (sense primer: 5'-GAAGGTGAAGGTCGGAGT-3', anti-sense primer: 5'-GAAGATGGTGATGGGATTTC-3') was used as a housekeeping gene, in order to normalize the expression of target genes. The reaction mix consisted of $6 \mathrm{mmol} / \mathrm{L}$ $\mathrm{MgCl}_{2}, 0.4 \mu \mathrm{l}$ LightCycler-RT-PCR Enzyme Mix and 4 $\mu \mathrm{l}$ LightCycler-RT-PCR Reaction Mix SYBR Green I. All oligonucleotide primers were designed and synthesized by Sangon (Shanghai, China). All primers used were at $0.5 \mu \mathrm{mol} / \mathrm{L}$ final concentration. The thermal cycling 
conditions were as follows: $10 \mathrm{~min}$ at $55^{\circ} \mathrm{C}$ for reverse transcription, 30 seconds at $95^{\circ} \mathrm{C}$ for pre-denaturation, 42 cycles for 1 second at $95^{\circ} \mathrm{C}$ for denaturation, $10 \mathrm{sec}-$ onds at $62^{\circ} \mathrm{C}$ for annealing and finally, 13 seconds at $72^{\circ}$ $\mathrm{C}$ for elongation. At the end of each cycle, the fluorescence emitted by the SYBR Green I was measured. After completion of the cycling process, samples were immediately subjected to a temperature ramp for melting curve analysis. The relative abundance of target mRNA in each sample was calculated using the formula suggested by Muller et al[20] which is given by $2^{-(\mathrm{IL}-8}$ Threshold Cycle) $/ 2^{-(\beta \text {-actin Threshold Cycle })} \times 10^{6}$.

\section{Western blot analysis}

Total proteins extracted from Hep-2 cells were separated on $10 \%$ or $15 \%$ DS-polyacrylamide gels. The procedure was briefly described as following: 40 micrograms of cell extract was separated electrophoretically using sodium dodecyl sulfate-polyacrylamide gel electrophoresis gel and transferred to nitrocellulose membranes. The membrane was blocked with $3 \%$ milk powder in nonfat milk in phosphate-buffered saline (PBS) at room temperature for 6-8 hours, washed with PBST (PBS containing 0.1\% Tween-20) for 10 min three times. The blot was incubated overnight at $4^{\circ} \mathrm{C}$ with rabbit anti-ATM monoclonal antibody per $\mathrm{mL}$ in PBS containing $2.5 \%$ nonfat milk, $2.5 \%$ bovine serum albumin (BSA), and $0.1 \%$ Tween 20 . The membrane was washed with PBS containing 0.1\% Tween 20 for $15 \mathrm{~min}$ $(\times 4)$. The membrane was incubated with alkaline phosphatase-labeled anti-mouse IgG antibody in TBS containing $1 \%$ milk powder at room temperature for 1 hour and washed again with TBS for $15 \mathrm{~min}(\times 1)$, then $5 \mathrm{~min}$ $(\times 4)$. Using the BCIP/NBT alkaline phosphatases substrate kit IV, the membrane was briefly visualized. Reactive bands were scanned by Gel Doc 1000 (Bio-Rad). The experiment was repeated three times.

\section{Irradiation}

GWGP-60 Precise radiation system (Beijing, China) was used to irradiate cells and solid tumor. X-ray irradiation was carried out at room temperature at a dose rate of $200 \mathrm{cGy} / \mathrm{min}$ and equipped with an external $0.5-\mathrm{mm}$ copper filter.

\section{Clonogenic survival assay}

Preliminary studies were conducted to optimize the number of cells plated in clonogenic assays, aiming at 100 colonies per well. The Hep-2 cells were seeded in triplicate at limiting dilutions in 6-well plates for about 24 hours in RPMI-1640 medium supplemented with $10 \%$ FBS. Then the cells were transfected with ATM AS-ODNs, ATM Sen-ODNs and Mis-ODNs respectively. About 18 hours after transfection, they were irradiated simultaneously with different doses of X-ray radiation $(0,2,4,6$, and 8 Gy) respectively. The medium was replaced with a fresh one 24 hours after irradiation. Colonies were fixed and stained with $0.5 \%$ crystal violet, and the number of colonies containing at least 50 cells, as examined by microscopy, was recorded 3 to 7 days later. In each irradiation dose group, surviving fraction (SF) of cells was calculated as plating efficiency of the irradiated cells divided by the plating efficiency of untreated samples.

\section{Apoptosis analyzed by flow cytometry}

After 48 hours exposed to 4 Gy radiation, Hep- 2 cells were harvested, and centrifuged at $1500 \mathrm{rpm}$ for $2 \mathrm{~min}$. Then cells were washed with PBS twice, and fixed in ice-cold $70 \%$ ethanol at $4^{\circ} \mathrm{C}$ overnight. After rinsing $1 \times$ 105-1 $\times 106$ cells with $1 \times$ Binding Buffer, the cells were reharvested and resuspended in $200 \mu \mathrm{l}$ of $1 \times$ Binding Buffer. $5 \mu \mathrm{l}$ of Annexin V and $10 \mu \mathrm{l}$ of Propidium Iodide (PI) were added in cells incubating at room temperature for $15 \mathrm{~min}$ in the dark. Cell apoptotic rate were analyzed by flow cytometry (Elite ESP, BeckmanCoulter, USA).

\section{Animal experiment}

Female BALB/c-nu/nu mice were used to investigate the effect of ATM AS-ODNs on radio-induced apoptosis of Hep-2 cells solid tumor. All surgical procedures and care administered to the animals were in accordance with institutional guidelines. Animal surgeries and radiotherapy were performed under general anesthesia, 50 $\mathrm{mg} / \mathrm{kg}$ ip injection of pentobarbital sodium. About $1 \times$ $10^{5}$ Hep-2 cells were subcutaneously inoculated in submental space of the mice. Tumor growth rates were determined by measuring two orthogonal dimensional diameters of each tumor thrice a week. Tumor volumes were calculated according to the formula $V=\pi / 6 \times a^{2}$ $x b$, where $a$ is the short axis, and $b$ the long axis. When tumors reached an average volume of about 200 $\mathrm{mm} 3$, the tumor-bearing BALB/c-nu/nu mice were divided into four groups assigned 8 nude mice in each group: (a) control group, no treatment; (b) ATM ASODNs group, tumors were treated with ATM AS-ODNs alone but not exposed to irradiation for each time; (c) irradiation group, tumors were exposed to X-ray of 2 Gy alone for each time; and (d) combination group, $2.5 \mathrm{mg} / \mathrm{kg}$ of ATM AS-ODNs was injected into the solid tumor the day before X-ray exposure, another dosage of ATM AS-ODNs was injected right before exposure to 2 Gy of X-ray for each time. The same treatment for each group was repeated 3 times (the interval time was 5 days). BALB/c-nu/nu mice were killed 3 weeks later. The ATM protein expression of the tumor in the different groups was analyzed by western blot using the procedures described as above. The tumor inhibition rate 


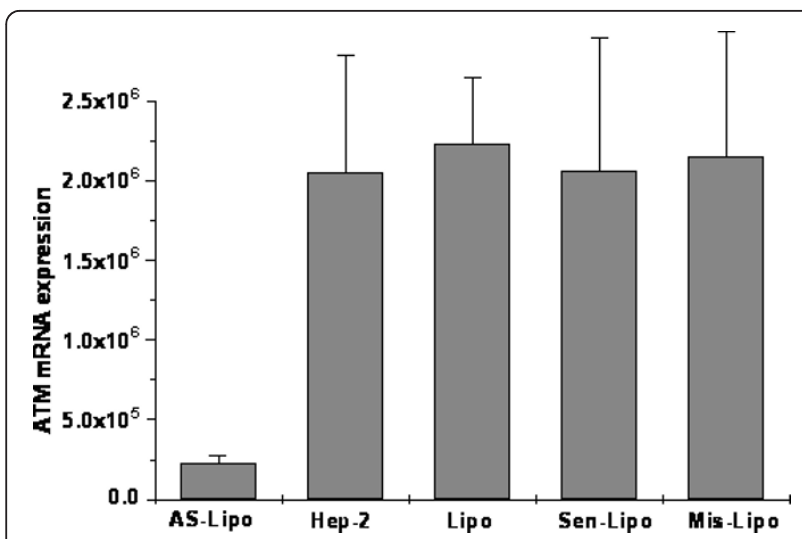

Figure 1 Real-time quantitative PCR analysis of ATM mRNA expression. Liposome formulations of ATM AS-ODNs decreased expression of ATM mRNA was notably lower than that of other groups. There are no significant differences among liposome-treated group (Lipo), Sen-ODNs (Sen-Lipo) treated group and Mis-ODNs (Mis-Lipo) treated group $(P>0.05) . P<0.05$, AS-ODNs (AS-Lipo) treated group compared with other groups.

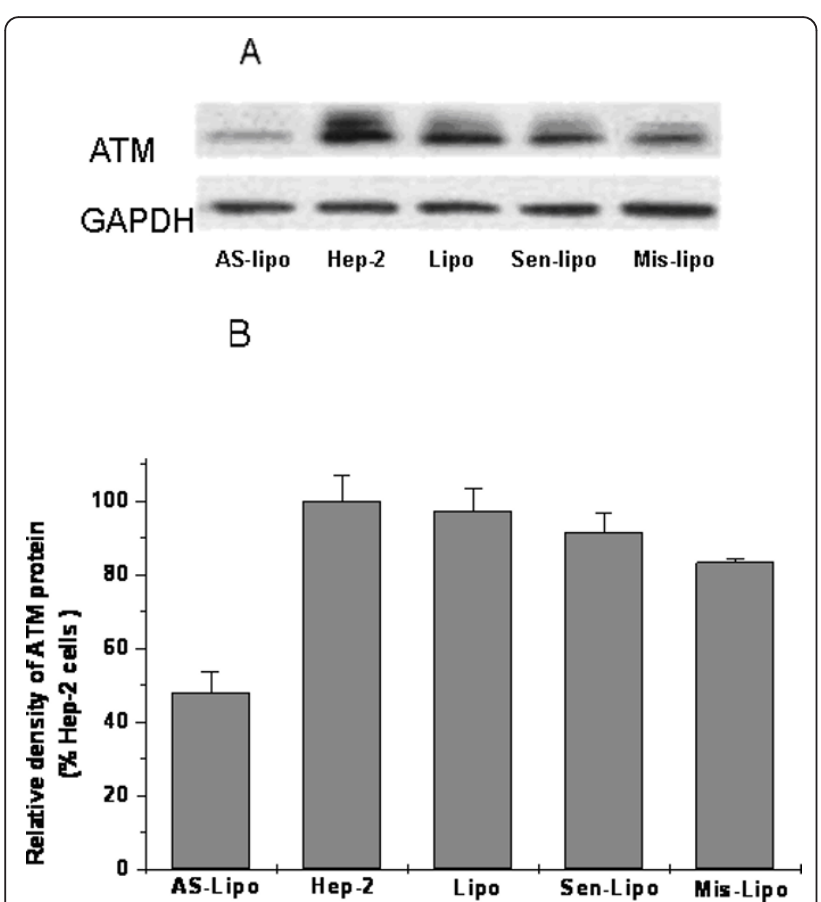

Figure 2 A Effect of ATM AS-ODNs on the expression of ATM protein in vitro. (A) Liposome formulations of ATM AS-ODNs dramatically reduced the expression of ATM protein compared with other groups. (B) There are no significant differences among liposome-treated group (Lipo), Sen-ODNs (Sen-Lipo) treated group and Mis-ODNs (Mis-Lipo) treated group ( $P>0.05)$, while the group treated with ATM AS-ODNs notably different compared with other groups (**P $<0.05)$. was calculated using the following formula: (1-average tumor volume of experimental group/average tumor volume of control group) $\times 100 \%$.

\section{TUNEL assay}

TUNEL (Terminal deoxynucleotidyltransferase-mediated dUTPdigoxigenin nick-end-labeling) staining of tumor sections was performed using an in situ apoptosis detection kit (Roche, Shanghai, China) according to the manufacture's protocol. The total number of apoptotic cells in 10 randomly selected fields was counted. The apoptotic index (AI) was calculated as the percentage of positive staining cells, namely $\mathrm{AI}=$ number of apoptotic cells $\times 100 /$ total number of nucleated cells.

\section{Statistics}

Results were expressed as mean \pm standard deviation (SD) and were analyzed with a one-way ANOVA and SPSS18.0 software package used to perform statistical analysis. A value of $\mathrm{P}<0.05$ was considered significant between the experimental groups compared with other groups.

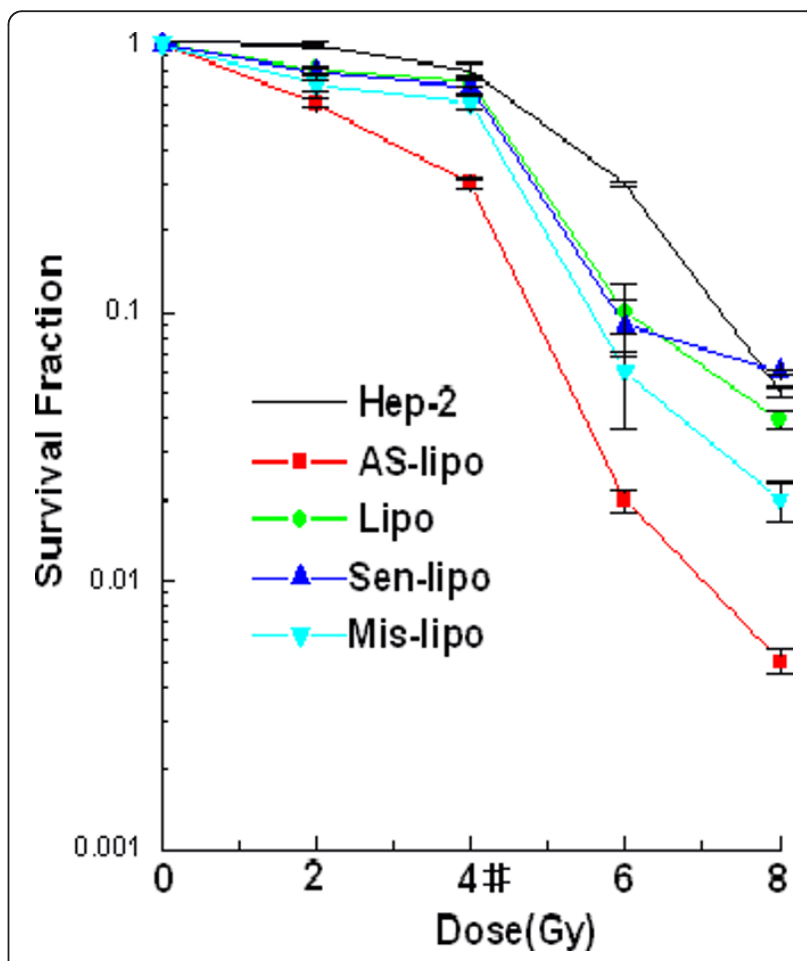

Figure 3 Survival curves for Hep-2 cells after irradiation. Survival fractions at each dose point were normalized to untreated cells. ${ }^{*} P<0.05$, the mean of SF4 in the cells transfected with ATM AS-ODNs was significantly lower than that of other cells. 


\section{Results}

Expression of ATM in ATM AS-ODNs transfected Hep-2 cells

To analyze the expression of ATM in mRNA and protein level in Hep-2 cells, real-time fluorescent quantitative PCR and western blot assay were used respectively. It is evident that there were no significant differences among the groups treated with liposome alone, with Sen-ODNs and with Mis-ODNs after 72 hours treatment $(\mathrm{P}>0.05$; Figure 1$)$. However when incubated with liposome formulations of ATM ASODNs, the relative ATM mRNA expression was only about $11.03 \pm 2.51 \%$ to the untreated Hep- 2 cells, which showed a significantly reduced expression of ATM mRNA $(\mathrm{P}<0.05$; Figure 1$)$. As shown in Figure 2, ATM protein expression was also significantly reduced by ATM AS-ODNs compared with SenODNs and Mis-ODNs after 72 hours treatment
(Figure 2A). The relative ATM protein expression of Hep-2 cells treated with ATM AS-ODNs was only about $48.14 \pm 5.53 \%$ to the untreated cells $(\mathrm{P}<0.05$; Figure 2B). But there was no significant difference among the group treated with liposome alone, the group treated with Sen-ODNs, the group treated with Mis-ODNs and the group of control untreated Hep-2 cells $(\mathrm{P}>0.05$; Figure $2 \mathrm{~B})$.

\section{ATM AS-ODNs on clonogenic survival ability of Hep-2} cells after irradiation

Cloning efficiency, $\mathrm{P}<0.05$, was declined in cells transfected with ATM AS-ODNs compared with untreated cells or cells treated with control at the identical radioactive dose (Figure 3). After 4 Gy radiation, the survival fraction (SF4) revealed the cellular radio-induced apoptosis. The SF4 of cells transfected with ATM AS-ODNs was $31.3 \pm 5.1 \%$, notably lower than that of other cells,

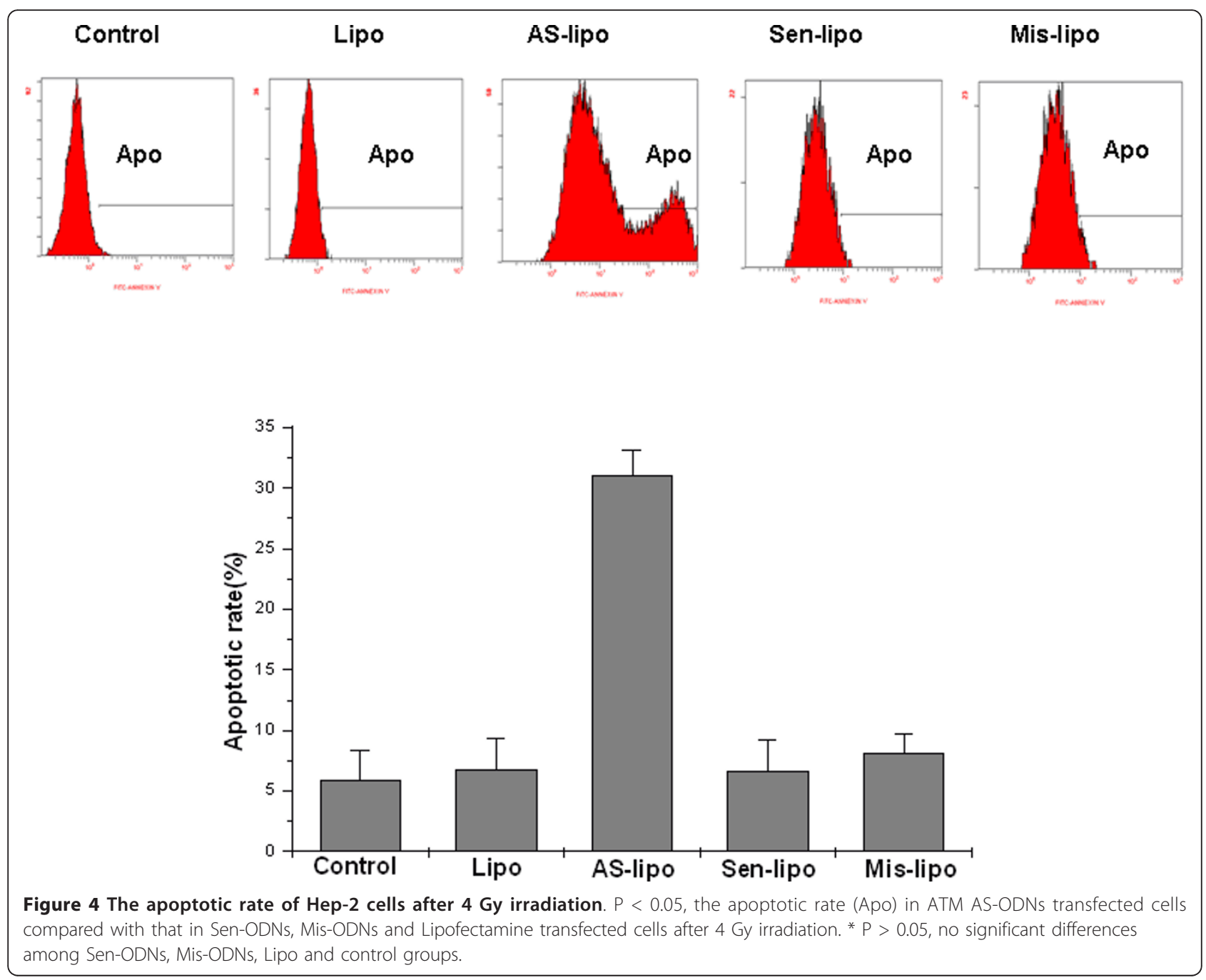


which indicated a definite increase in the radio-induced apoptosis $(\mathrm{P}<0.05$; Figure 3$)$. In clonogenic survival ability, there were no significant differences compared with other groups ( $\mathrm{P}>0.05$; Figure 3$)$.

\section{Apoptosis of Hep-2 cells after irradiation in vitro}

After 4 Gy irradiation, the apoptotic rate in ATM ASODNs transfected cells was $30.7 \pm 1.31 \%$, which was higher than that in Sen-ODNs and Mis-ODNs transfected cells $(\mathrm{P}<0.05$; Figure 4$)$.

\section{Inhibitory effect of ATM AS-ODNs on tumor growth in vivo after irradiation}

The homologous ATM protein expression were only $76.84 \pm 3.12 \%$ and $48.19 \pm 3.98 \%$ to the untreated group respectively in the group treated with ATM AS-ODNs alone and the group irradiated in combination with the treatment of ATM AS-ODNs $(\mathrm{P}<0.05$; Figure 5). Tumor growth of the mice in four groups was shown in Figure 5. The inhibition rate in Hep-2 cells solid tumor treated in X-ray alone was $5.95 \pm 4.52 \%$, while it was $34.28 \pm 2.43 \%$ in solid tumor irradiated in combination with the treatment of ATM AS-ODNs at the experimental endpoint $(\mathrm{P}<0.05$; Figure 5$)$.

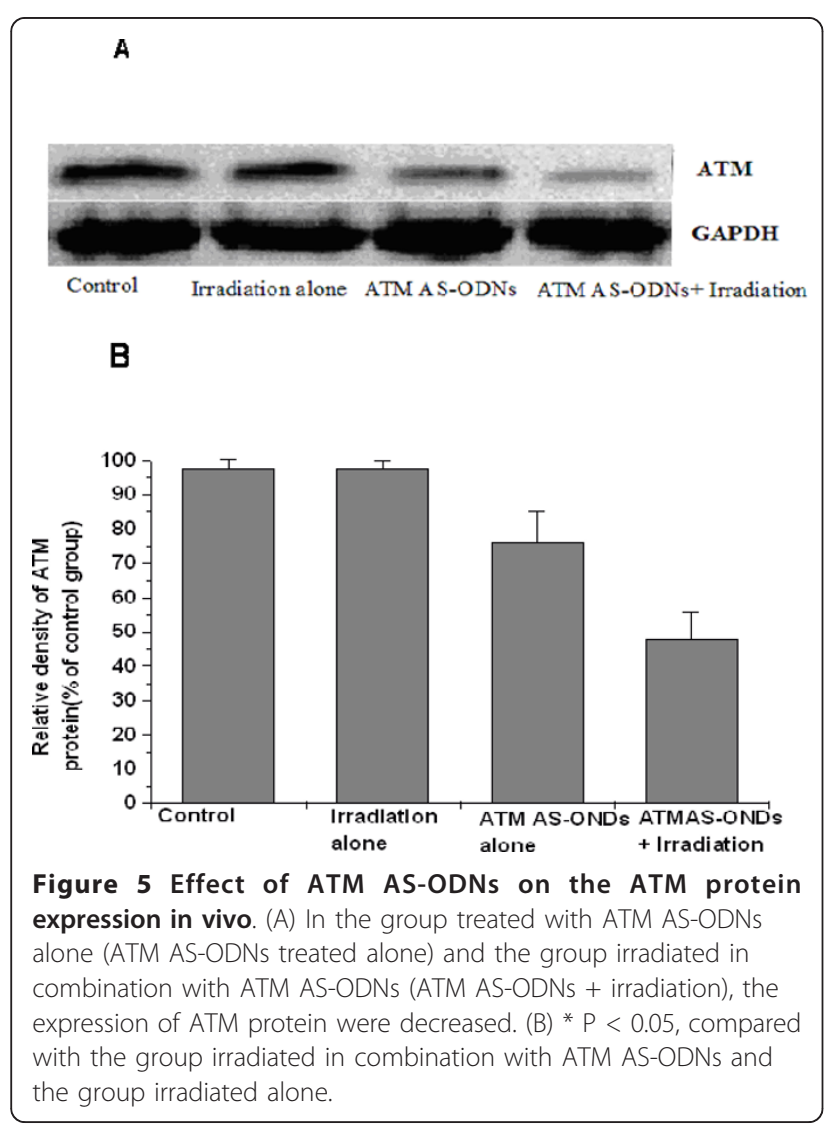

Enhancement of tumor apoptosis by irradiation combined with ATM AS-ODNs treatment in vivo

There were small numbers of apoptotic cells detected by TUNEL analysis in tumors treated with irradiation alone, while the group treated with irradiation in combination with ATM AS-ODNs was notably higher than that of irradiation alone (Figure 7A). Accordingly, the AI for mice tumors treated with irradiation in combination with ATM AS-ODNs was $17.12 \pm 4.2 \%$, significantly higher than that of the other groups $(\mathrm{P}<0.05$; Figure $7 \mathrm{~B})$.

\section{Discussion}

Phosphorylation of several DNA damage response proteins, including ATM, p53, can be observed in precursor stage cancers of the breast, colon, lung, skin, testes, and urinary bladder [21-23]. It may suggest that DNA damage occurs during the earliest stages of tumor development, before genomic instability and the loss of wild-type p53 function in many cancers. Raju $\mathrm{V}$ have demonstrated that p53 induction in response to Myc overexpression requires the ataxia-telangiectasia mutated (ATM) kinase, a major regulator of the cellular response to DNA double-strand breaks[24]. Mohammad A speculated that ATM deficiency might increase the sensitivity of leukemic blasts to the chemotherapy used during induction and after disease remission in patients with adult ALL (Acute Lymphoblastic Leukemia) [25]. Jian confirmed that Antisense inhibition of ATM gene enhanced the radiosensitivity of head and neck squamous cell carcinoma in mice. Therefore we designed the experiment to verify the hypothesis whether ATM AS-ODNs could inhibit the expression of ATM in Hep-2 cells and furthermore increase the radio-induced apoptosis in vitro and in vivo.

Here we show that transgenic expression of ATM ASODNs into hep- 2 cells on its own induced the inhibitory expression of ATM at mRNA and protein level in hep-2 cells. We detected that expression of ATM was notably

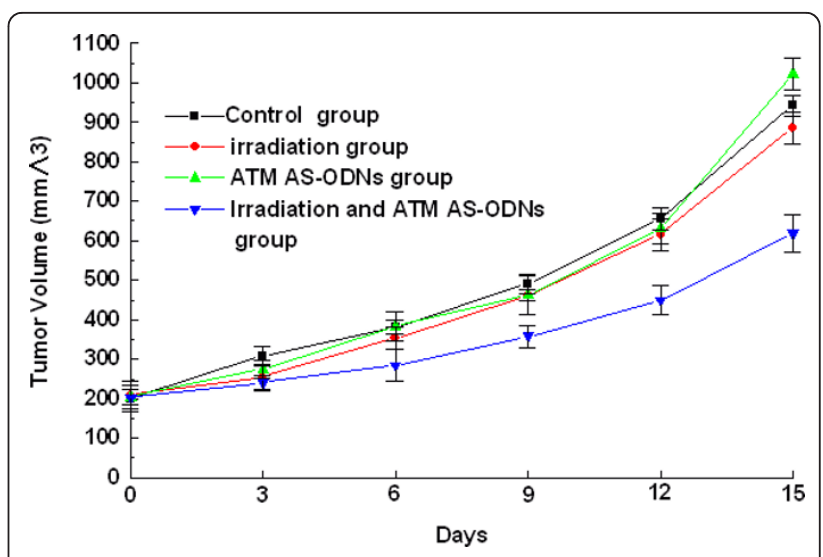

Figure 6 Tumor growth in ATM AS-ODNs treated Hep-2 cells in $B A L B / c-n u / n u$ mice with or without irradiation. 


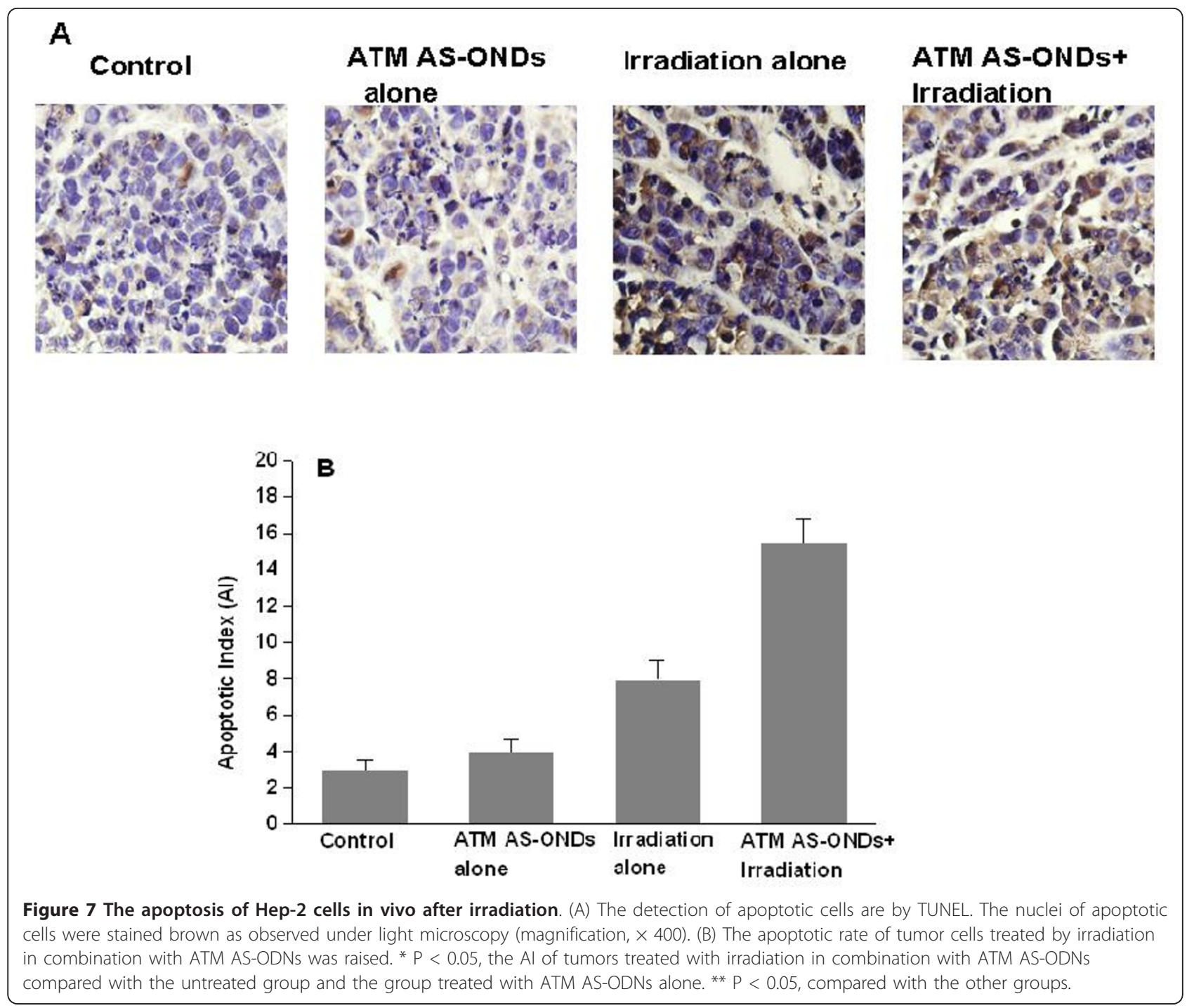

lower after cell transfection with ATM AS-ODNs than Sen-ODNs, Mis-ODNs and control ODNs, which showed that the inhibition was specific for the ATM antisense sequence. Then we studied whether the reduction of ATM expression resulted in radio-induced apoptosis enhancing in hep- 2 cells. The results of clonogenic survival assay and SF4 demonstrated that the cloning efficiency and SF4 declined notably in cells transfected with ATM AS-ODNs at the same dose of radiation $(\mathrm{P}<$ 0.05) compared with untreated cells or cells treated with liposome, which means the increase of cell apoptosis. By flow cytometry, we found that the apoptotic rate (Apo) in ATM AS-ODNs treated cells was higher than that in Sen-ODNs and Mis-ODNs treated cells after irradiation.

In the study, we also investigated the effects of ATM AS-ODNs on the apoptotic responses to ionizing radiation in vivo. It was obvious that there were a significant difference between the tumors irradiated in combination with the treatment of ATM AS-ODNs and controlling tumor. The inhibition rate in the tumors injected with ATM AS-ODNs before exposure to X-ray was $34.28 \pm$ $2.43 \%$, whereas it was $5.95 \pm 4.52 \%$ in tumors exposed to radiation alone $(\mathrm{P}<0.05)$. The results of TUNEL assay demonstrated that the apoptotic rate of the tumors irradiated in combination with the treatment of ATM AS-ODNs was notably higher than that of control groups. The findings in vivo experiments manifested that the radio-induced apoptosis of hep- 2 cells in solid tumors were enhanced by the treatment of ATM ASODNs, which may be related with the increased radiosensitivity and radiation-induced apoptosis. Jian and colleagues have shown that antisense oligodeoxynucleotides of ATM enhances the radiosensitivity of head and neck squamous cell carcinoma in mice $[16,17]$. We had demonstrated that the ATM AS-ODNs could specifically reduce the ATM expression and increase radio-induced 
apoptosis in hep-2 cell line. It is first reported with ASODNs of ATM strengthening radio-induced apoptosis of hep-2 cell line grown in nude mice.

In conclusion, radiotherapy combined with AS-ODNs could specifically reduce the ATM expression and increase radio-induced apoptosis in hep- 2 cell line. This approach might have great potential for the clinical treatment of many tumors.

\section{Conclusion}

We had demonstrated that the ATM AS-ODNs could specifically reduce the ATM expression and increase radio-induced apoptosis in hep- 2 cells in vitro and in vivo in our study.

\section{Acknowledgements}

This work was supported by grants from the National Natural Science Foundation of China (No.30872850), the Sichuan Provincial Science Supporting Foundation (No.2008sz0186) and Youth Foundation of Sichuan University (No.2008099). We also thank Dr. Hongwei Yan (Institute of foreign language, North Sichuan Medical College, Nanchong, PR China 637000) for correcting English of the manuscript. We thank Baogian Jing (Institute of molecular organism, North Sichuan Medical College, Nanchong, PR China 637000) for technical assistance.

\section{Author details}

${ }^{1}$ From the Department of Otolaryngology-Head and Neck Surgery, West China hospital of Sichuan University, Chengdu, PR China 610041.

2Department of pathobiology, North Sichuan Medical College, Nanchong, PR China 637000. ${ }^{3}$ Department of cardiothoracia Surgery, West China hospital of Sichuan University, Chengdu, PR China 610041. ${ }^{4}$ Sichuan University and working in the Affiliated Hospital of North Sichuan Medical College.

\section{Authors' contributions}

JZ participated in the design of the study and performed the statistical analysis. LL carried out cell culture and flow cytometry assay, participated in the animal experiment. YZ participated in irradiation for cells and animals. SL conceived of the study, and participated in its design and coordination and helped to draft the manuscript. JF designed the study, performed the rest of the experiments and wrote the manuscript. All authors read and approved the final manuscript.

\section{Competing interests}

The authors declare that they have no competing interests.

Received: 27 December 2010 Accepted: 17 April 2011

Published: 17 April 2011

\section{References}

1. Rhee JG, Li D, O'Malley BW Jr, Suntharalingam M: Combination radiation and adenovirus-mediated P16 (INK4A) gene therapy in a murine model for head and neck cancer. ORL; journal for oto-rhino-laryngology and its related specialties 2003, 65:144-54

2. Rhee JG, Li D, Suntharalingam M, Guo C, O'Malley BW Jr, Carney JP: Radiosensitization of head/neck squamous cell carcinoma by adenovirus-mediated expression of the Nbs1 protein. International journal of radiation oncology, biology, physics 2007, 67:273-8.

3. Hristov B, Bajaj GK: Radiotherapeutic management of laryngeal carcinoma. Otolaryngologic clinics of North America 2008, 41(4):715-740.

4. Bhuller Yadvinder, Peter G, Wells : A Developmental Role for AtaxiaTelangiectasia Mutated in Protecting the Embryo from Spontaneous and Phenytoin-Enhanced Embryopathies in Culture. Toxicological Sciences 2006, 93(1):156-163.

5. Li Y, Carty MP, Oakley GG, Seidman MM, Medvedovic M, Dixon K: Expression of ATM in ataxia telangiectasia fibroblasts rescues defects in DNA double-strand break repair in nuclear extracts. Environmental and molecular mutagenesis 2001, 37:128-40.
6. El-Awady RA, Dikomey E, Dahm-Daphi J: Radiosensitivity of human tumor cells is correlated with the induction but not with the repair of DNA double-strand breaks. British journal of cancer 2003, 89:593-601.

7. Sakata K, Someya M, Matsumoto Y, Hareyama M: Ability to repair DNA double-strand breaks related to cancer susceptibility and radiosensitivity. Radiation medicine 2007, 25:433-8.

8. Winrow JChristopher, Pankratz GDaniel, Vibat Rose T Cecile: Aberrant recombination involving the granzyme locus occurs in $\mathrm{Atm}^{-/} \mathrm{T}$-cell lymphomas. Human Molecular Genetics 2005, 14(18):2671-2684:.

9. Helt CE, Cliby WA, Keng PC, Bambara RA, O'Reilly MA: Ataxia telangiectasia mutated (ATM) and ATM and Rad3-related protein exhibit selective target specificities in response to different forms of DNA damage. J Biol Chem 2005, 280:1186-92.

10. Barzilai A, Rotman G, Shiloh Y: ATM deficiency and oxidative stress: a new dimension of defective response to DNA damage. DNA Repair (Amst) 2002, 1:3-25.

11. Kastan MB, Lim DS: The many substrates and functions of ATM. Nat Rev Mol Cell Biol 2000, 1:179-186.

12. Herzog KH, Chong MJ, Kapsetaki M, Morgan Jl, McKinnon PJ: Requirement for Atm in ionizing radiation-induced cell death in the developing central nervous system. Science 1998, 280:1089-91.

13. Chong MJ, Murray MR, Gosink EC, Russell HR, Srinivasan A, Kapsetaki M, Korsmeyer SJ, McKinnon PJ: Atm and Bax cooperate in ionizing radiationinduced apoptosis in the central nervous system. Proc Natl Acad Sci USA 2000, 97:889-94.

14. Lee Y, Chong MJ, McKinnon PJ: Ataxia telangiectasia mutated-dependent apoptosis after genotoxic stress in the developing nervous system is determined by cellular differentiation status. J Neurosci 2001, 21:6687-93.

15. Borges HL, Chao C, Xu Y, Linden R, Wang JY: Radiation-induced apoptosis in developing mouse retina exhibits dose-dependent requirement for ATM phosphorylation of p53. Cell Death Differ 2004, 11:494-502.

16. Zou Jian, Qiao Xiaoming, Ye Huiping, et al: Antisense inhibition of ATM gene enhances the radiosensitivity of head and neck squamous cell carcinoma in mice. Journal of Experimental \& Clinical Cancer Research 2008, 27:56.

17. Van Waes Carter: Molecular Biology of Squamous Cell Carcinoma. Head and neck surgery 997-1003.

18. Sak A, Stuschke M, Wurm R, et al: Selective inactivation of DNAdependent protein kinase with antisense oligodeoxynucleotides: consequences for the rejoining of radiation-induced DNA double-strand breaks and radiosensitivity of human cancer cell lines. Cancer Res 2002, 62(22):6621-4.

19. Leonard CE, Chan DC, Chou TC, et al: Paclitaxel enhances in vitro radiosensitivity of squamous carcinoma cell lines of the head and neck. Cancer Res 1996, 56(22):5198-204.

20. Muller PY, Janovjak H, Miserez AR, Dobbie Z: Processing of gene expression data generated by quantitative real-time RT-PCR. Biotechniques 2002, 32(6):1372-4, 1376, 1378-9.

21. Bartkova J, Horejsí Z, Koed K, Krämer A, Tort F, Zieger K, Guldberg P, Sehested M, Nesland JM, Lukas C, et al: DNA damage response as a candidate anti-cancer barrier in early human tumorigenesis. Nature 2005, 434(7035):864-70.

22. Gorgoulis VG, Vassiliou LV, Karakaidos P, Zacharatos P, Kotsinas A, Liloglou T, Venere M, Ditullio RA Jr, Kastrinakis NG, Levy B, Kletsas D, Yoneta A, Herlyn M, Kittas C, Halazonetis TD: Activation of the DNA damage checkpoint and genomic instability in human precancerous lesions. Nature 2005, 434(7035):907-13.

23. Bartkova J, Bakkenist CJ, Rajpert-De Meyts E, Skakkebaek NE, Sehested M, Lukas J, Kastan MB, Bartek J: ATM activation in normal human tissues and testicular cancer. Cell Cycle 2005, 4(6):838-45, Epub 2005 Jun 13.

24. Pusapati VRaju, Robert J, et al: ATM promotes apoptosis and suppresses tumorigenesis in response to Myc. Proc Natl Acad Sci USA 2006, 103(5):1446-1451.

25. Haidar AMohammad, Kantarijian Hagop, Manshouri Taghi, et al: ATM Gene Deletion in Patients with Adult Acute Lymphoblastic Leukemia. CANCER 2000, 5:1057-1062.

doi:10.1186/1756-9966-30-43

Cite this article as: Feng et al:: Antisense oligodeoxynucleotides targeting ATM strengthen apoptosis of laryngeal squamous cell carcinoma grown in nude mice. Journal of Experimental \& Clinical Cancer Research 2011 30:43. 